\title{
Investigation on the Tunable-Length Zinc Oxide Nanowire Arrays for Dye-Sensitized Solar Cells
}

\author{
Shou-Yi Kuo, ${ }^{1,2}$ Ming-Yang Hsieh, ${ }^{1}$ and Hsin-I Lin ${ }^{1}$ \\ ${ }^{1}$ Department of Electronic Engineering, Chang Gung University, 259 Wen-Hwa 1st Road, Kwei-Shan, Taoyuan 333, Taiwan \\ ${ }^{2}$ Green Technology Research Center, Chang Gung University, Taiwan \\ Correspondence should be addressed to Shou-Yi Kuo; sykuo@mail.cgu.edu.tw
}

Received 6 January 2014; Revised 7 April 2014; Accepted 7 April 2014; Published 29 April 2014

Academic Editor: Vincenzo Augugliaro

Copyright (c) 2014 Shou-Yi Kuo et al. This is an open access article distributed under the Creative Commons Attribution License, which permits unrestricted use, distribution, and reproduction in any medium, provided the original work is properly cited.

\begin{abstract}
We had successfully fabricated $\mathrm{ZnO}$-based nanowires by vapor transport method in the furnace tube. ZnO nanowire arrays grown in $600^{\circ} \mathrm{C}$ for 30 minutes, 60 minutes, 90 minutes, and 120 minutes had applied to the dye-sensitized solar cells. The dye loading is proportional to the total equivalent surface area of $\mathrm{ZnO}$ nanowire arrays in the cells and plays an important role in improving power conversion efficiency. The highest efficiency was observed in DSSC sample with $\mathrm{ZnO}$ nanowires grown for 90 minutes, which had the largest equivalent surface area and also the highest dye loading. According to our experimental results, the enhancement in power conversion efficiency is attributed to the higher light harvesting and reduction of carrier recombination. In addition, $\mathrm{ZnO}$ nanowires also contribute to the photocurrent in the UV region.
\end{abstract}

\section{Introduction}

Due to the low fabrication cost and relatively high efficiency, dye-sensitized solar cells (DSSCs) have been a potential alternative to $\mathrm{p}-\mathrm{n}$ junction solar cells [1-3]. The porous $\mathrm{TiO}_{2}$ based DSSCs have overcome the shortcomings of expensive cost related to the construction of photovoltaic modules for solid-state devices. The structure of porous $\mathrm{TiO}_{2}$ nanoparticles provides a large surface area for anchoring the lightharvesting dye molecules. However, the conversion efficiency of nanoporous $\mathrm{TiO}_{2}$-based DSSCs had stuck at around 11$12 \%$ due to the restricted electron extraction efficiency that resulted from slow electron transport mechanism and chargecarrier recombination by grain boundaries [4]. To significantly improve the electron transport efficiency, it is expected to synthesize promising type of nanomaterial instead of nanoparticle to generate a direct conduction pathway to the collecting electrode.

In addition to the use of $\mathrm{TiO}_{2}$ structures for the fabrication of DSSCs, heretofore, several other semiconductor materials, such as $\mathrm{ZnO}, \mathrm{Cd}(\mathrm{Se}, \mathrm{S})$, and $\mathrm{SnO}_{2}$, have also been employed as an electrode material in DSSCs [5]. Among these materials, $\mathrm{ZnO}$ is one promising II-VI compound oxide semiconductor material with its wide direct band gap of $3.37 \mathrm{eV}$ at room temperature, strong exciton binding energy of $60 \mathrm{meV}$, and great physical and chemical stability [6-8]. ZnO-based DSSCs are believed to gain the enhancement of efficiency because of their rapid electron transfer, reduction of charge recombination degree, and collection of carriers through electrical transport pathway. However, overall solarto-electric energy conversion efficiency $(\eta)$ of $\mathrm{ZnO}$-based DSSCs is still relatively low [9-11]. Recently, more researchers have been focused on the nanostructured $\mathrm{ZnO}$ materials to improve the efficiency of $\mathrm{ZnO}$-based cells using, especially $\mathrm{ZnO}$ one-dimensional (1D) structure [12-14].

There are many technologies to grow $\mathrm{ZnO} 1 \mathrm{D}$ structure including vapor-liquid-solid process [15], metalorganic chemical vapor deposition [16], thermal evaporation [17], and chemical solution synthesis [18]. The properties of $1 \mathrm{D} \mathrm{ZnO}$ are strongly dependent on the fabrication conditions used. Also, it has been shown that photovoltaic response of $\mathrm{ZnO}$ nanowires is dependent not only on the rod size but also on their orientation. Typically, the $\mathrm{ZnO} 1 \mathrm{D}$ nanostructures prepared by chemical solution method exhibit inferior material quality compared to vapor deposited samples. In this paper, we put emphasis on the influence of $\mathrm{ZnO}$ nanostructures 
prepared by vapor transport technique on dye adsorption and carrier transport rather than on efficiency.

\section{Experimental Procedure}

$\mathrm{ZnO}$ nanowires were grown on fluorine doped tin oxide (FTO) substrates. FTO conducting glass with $1 \times 1 \mathrm{~cm}^{2} \mathrm{Au}$ buffer layer and pure $\mathrm{Zn}$ powder (99.99\%) were inserted into the center of quartz tube. The quartz tube was evacuated by using mechanical pump. The high-purity argon gas was infused into the system with a flow rate of $200 \mathrm{sccm}$. The growth temperature of the furnace was increased to $600^{\circ} \mathrm{C}$ and maintained for 30, 60, 90, and 120 minutes. After the procedure the as-grown $\mathrm{ZnO}$ nanowires substrate was immersed to $0.3 \mathrm{mM}$ N719 dye for 24 hours and used acetonitrile to remove the unnecessary dye, and $\mathrm{Pt}$ film was formed on the other FTO substrate. Both substrates were coated on a film of Ag gel and, after that, the cell was assembled with $125 \mu \mathrm{m}$ surlyn film. The electrolyte $(0.5 \mathrm{M}$ 4-tert-butyl-pyridine + $0.05 \mathrm{M} \mathrm{I}_{2}+0.5 \mathrm{M} \mathrm{LiI}+0.6 \mathrm{M}$ tetrabutylammonium iodide) was injected to the cell and then sealed with UV gel.

Surface morphologies of the $\mathrm{ZnO}$ nanowires were examined using field-emission scanning electron microscope (FESEM). The conversion efficiency and current densityvoltage $(J-V)$ curve was characterized by a solar simulator (Yamashita Denso Xenon lamp power supply model YSS-50) with AM 1.5, $100 \mathrm{~mW} / \mathrm{cm}^{2} \mathrm{Xe}$ lamp as a photon source. The current-voltage digital meter (Keithley 2410) is attached to the solar simulator. The electrochemical impedance spectroscopy (EIS) was measured under the light illumination of AM $1.5\left(100 \mathrm{~mW} / \mathrm{cm}^{2}\right)$ with an impedance analyzer (Autolab PGSTAT 30) when a device was applied with its open-circuit voltage (Voc). An additional alternative sinusoidal voltage amplitude $10 \mathrm{mV}$ was also applied between an anode and a cathode of a device over the frequency range of $0.02 \sim 100 \mathrm{kHz}$.

\section{Results and Discussion}

Figure 1 shows the $\mathrm{XRD}$ results of the $\mathrm{ZnO}$ nanowires grown on the FTO conducting glasses. The reflections from FTO glass are present in all patterns. All $\mathrm{ZnO}$ nanowires samples have high intensity peak at (002) diffraction plane, indicating that $\mathrm{ZnO}$ nanowires are preferential perpendicular to the substrate in the direction of $c$-axis. No other peaks from impurities were found, showing the high purity of $\mathrm{ZnO}$ nanowires. SEM images of the high-density $\mathrm{ZnO}$ nanowires grown on the substrate are shown in Figure 2. The majority of the nanowires were grown with diameters of $454 \mathrm{~nm}, 383 \mathrm{~nm}$, $450 \mathrm{~nm}$, and $433 \mathrm{~nm}$ and lengths of $2.75 \mu \mathrm{m}, 7.17 \mu \mathrm{m}, 5.17 \mu \mathrm{m}$, and $4.33 \mu \mathrm{m}$ for growth durations of $30 \mathrm{~min}, 60 \mathrm{~min}, 90 \mathrm{~min}$, and $120 \mathrm{~min}$, respectively. Moreover, the density of $\mathrm{ZnO}$ nanowires samples is $3.8 \times 10^{8} \mathrm{~cm}^{-2}, 2.6 \times 10^{8} \mathrm{~cm}^{-2}, 4.6 \times$ $10^{8} \mathrm{~cm}^{-2}$, and $2.2 \times 10^{8} \mathrm{~cm}^{-2}$, respectively. The equivalent surface area of samples is counted and summarized in Table 1. The surface area of samples on $1 \times 1 \mathrm{~cm}^{2}$ FTO glass grown for $30 \mathrm{~min}, 60 \mathrm{~min}, 90 \mathrm{~min}$, and $120 \mathrm{~min}$ is $15.6 \mathrm{~cm}^{2}, 22.73 \mathrm{~cm}^{2}$, $34.22 \mathrm{~cm}^{2}$, and $13.28 \mathrm{~cm}^{2}$, respectively.

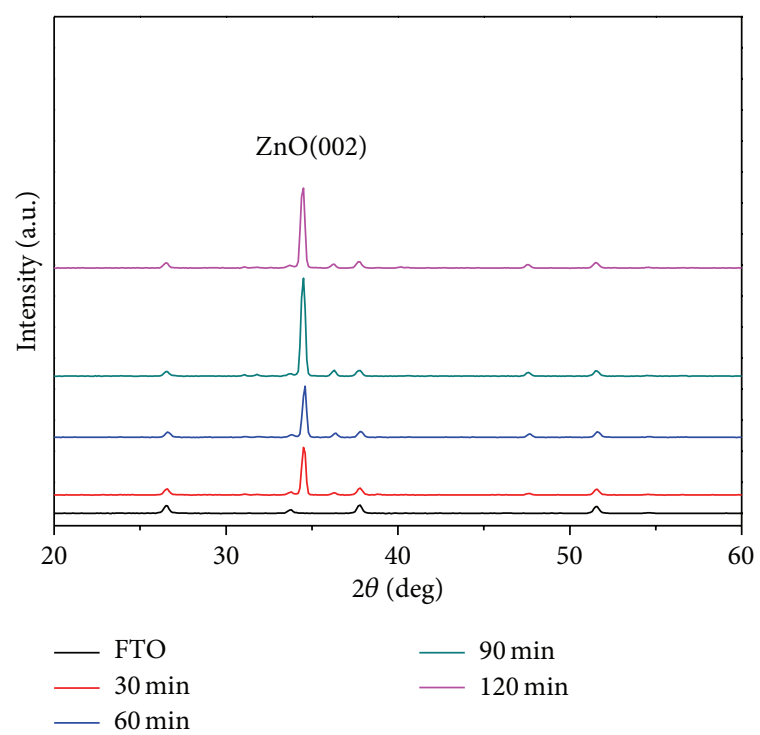

FIGURE 1: XRD spectra of $\mathrm{ZnO}$ nanowires grown on FTO conducting glass.

TABLE 1: Equivalent surface area of $\mathrm{ZnO}$ nanowires on $1 \times 1 \mathrm{~cm}^{2} \mathrm{FTO}$ glass with different growth time.

\begin{tabular}{lcccc}
\hline & $30 \mathrm{~min}$ & $60 \mathrm{~min}$ & $90 \mathrm{~min}$ & $120 \mathrm{~min}$ \\
\hline Equivalent & $4.97 \times 10^{-4}$ & $7.24 \times 10^{-4}$ & $1.09 \times 10^{-3}$ & $4.23 \times 10^{-4}$ \\
surface area & $\pi \mathrm{m}^{2} / \mathrm{cm}^{2}$ & $\pi \mathrm{m}^{2} / \mathrm{cm}^{2}$ & $\pi \mathrm{m}^{2} / \mathrm{cm}^{2}$ & $\pi \mathrm{m}^{2} / \mathrm{cm}^{2}$ \\
\hline
\end{tabular}

TABLE 2: Dye loading of $\mathrm{ZnO}$ nanowires with different growth time.

\begin{tabular}{lcccc}
\hline & $30 \mathrm{~min}$ & $60 \mathrm{~min}$ & $90 \mathrm{~min}$ & $120 \mathrm{~min}$ \\
\hline $\begin{array}{l}\text { Dye } \\
\text { loading }\end{array}$ & $5.95 \times 10^{-6} \mathrm{~g}$ & $1.12 \times 10^{-5} \mathrm{~g}$ & $1.32 \times 10^{-4} \mathrm{~g}$ & $4.07 \times 10^{-6} \mathrm{~g}$ \\
\hline
\end{tabular}

To emphasize the differences in the equivalent surface area of nanowires, dye loading was quantitatively determined by an ultraviolet/visible (UV-VIS) spectrophotometric method, after calibration using a diluted aqueous solution of N719 dye. It is known that the presence of the $\mathrm{OH}$ groups can also affect the dye loading, based on the obtained results for $\mathrm{ZnO}$ nanowires [16]. Therefore, dye loading was investigated and the obtained results for the absorbance of the desorbed dye are shown in Figure 3. From the results, the dye loading is counted and summarized in Table 2 . It seems that the dye loading of the samples is proportional to the total equivalent surface area of $\mathrm{ZnO}$ nanowire arrays in the cells. This phenomenon indicates that the more equivalent surface area of the $\mathrm{ZnO}$ nanowire arrays provides more opportunities to absorb the dye. The highest dye loading is obtained at samples grown for $90 \mathrm{~min}$, which is consistent with the SEM results mentioned above. The phenomenon can be comprehended as follows. As we increase the growth time from 30 minutes to 90 minutes, the vertical growth mechanism dominates the formation of one-dimensional nanowires. Moreover, two-dimensional growth mechanism will facilitate the two-dimensional growth while growth 


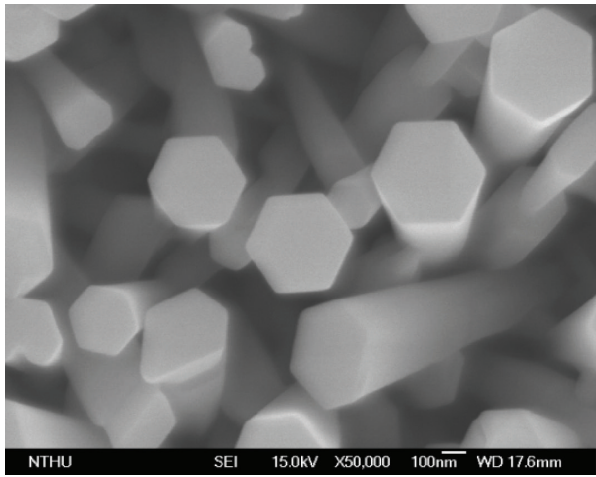

(a)

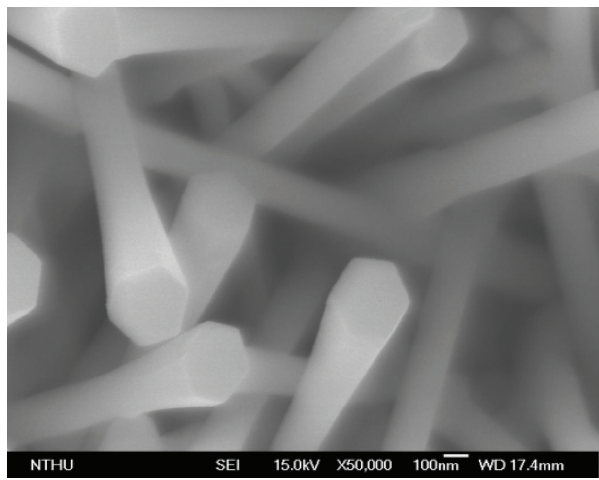

(c)

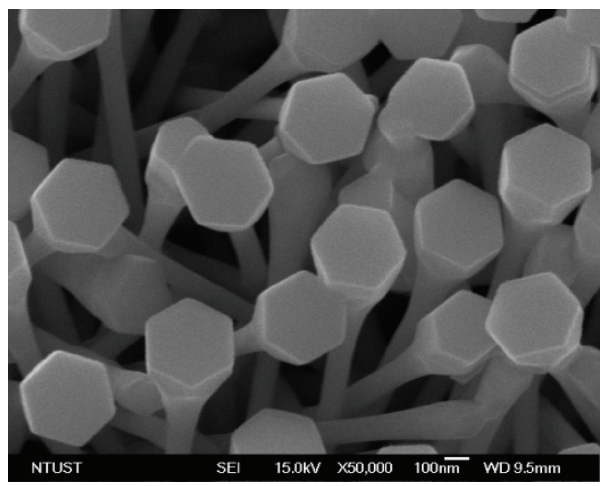

(e)

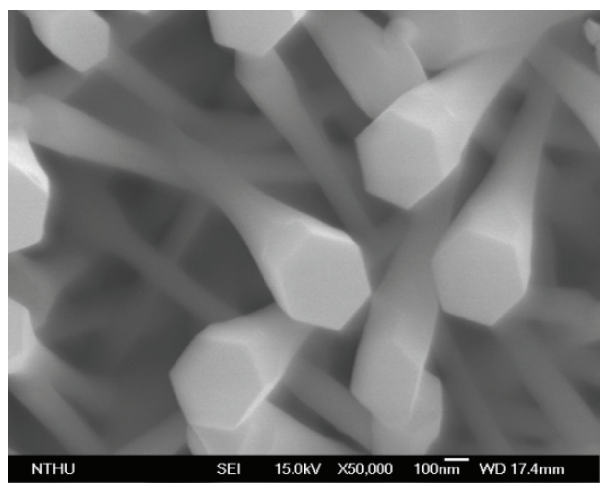

(g)

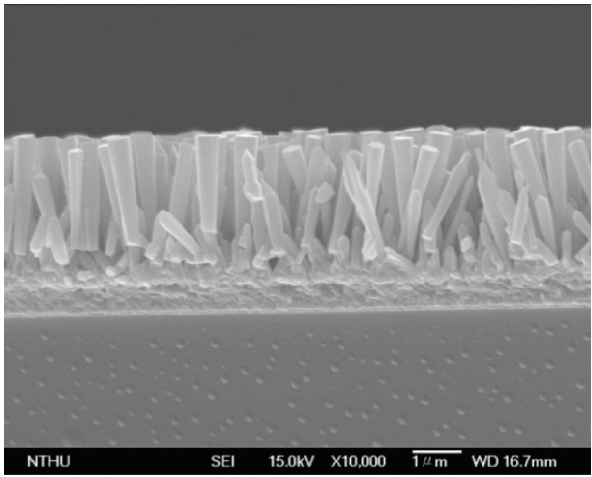

(b)

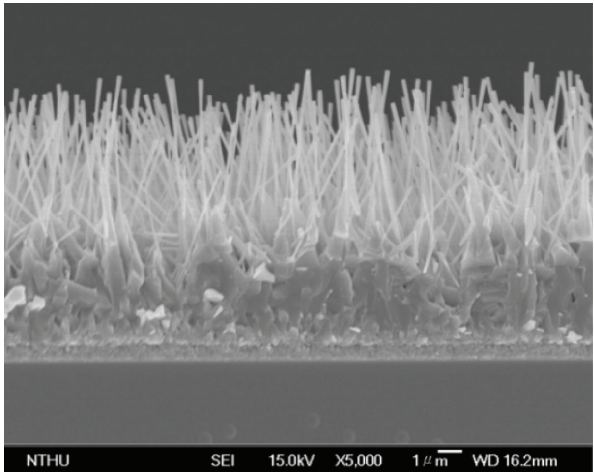

(d)

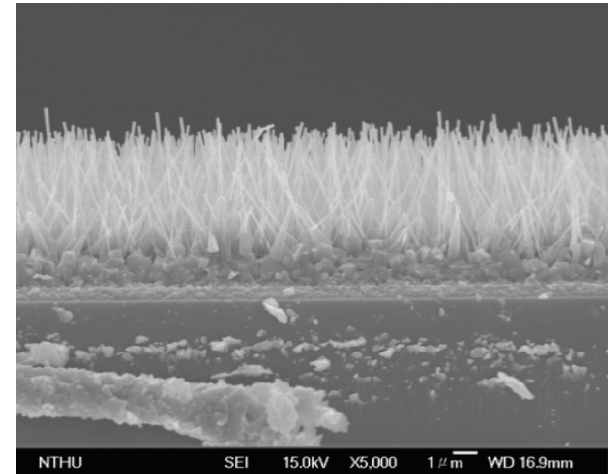

(f)

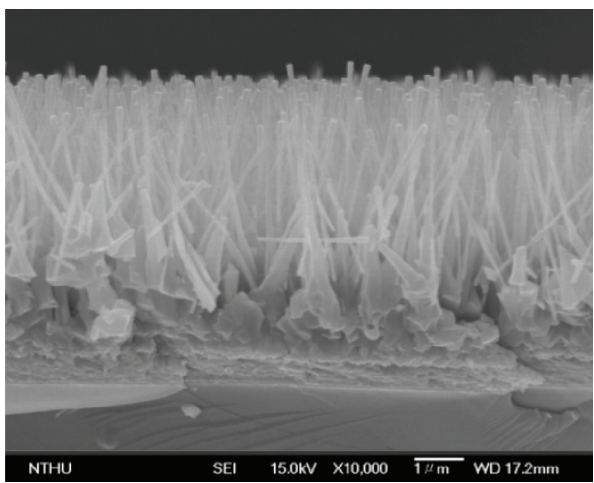

(h)

FIGURE 2: FE-SEM images of $\mathrm{ZnO}$ nanowires on the FTO conducting glass with different growth times: (a)-(b) for 30 minutes, (c)-(d) for 60 minutes, (e)-(f) for 90 minutes, and (g)-(h) for 120 minutes. 


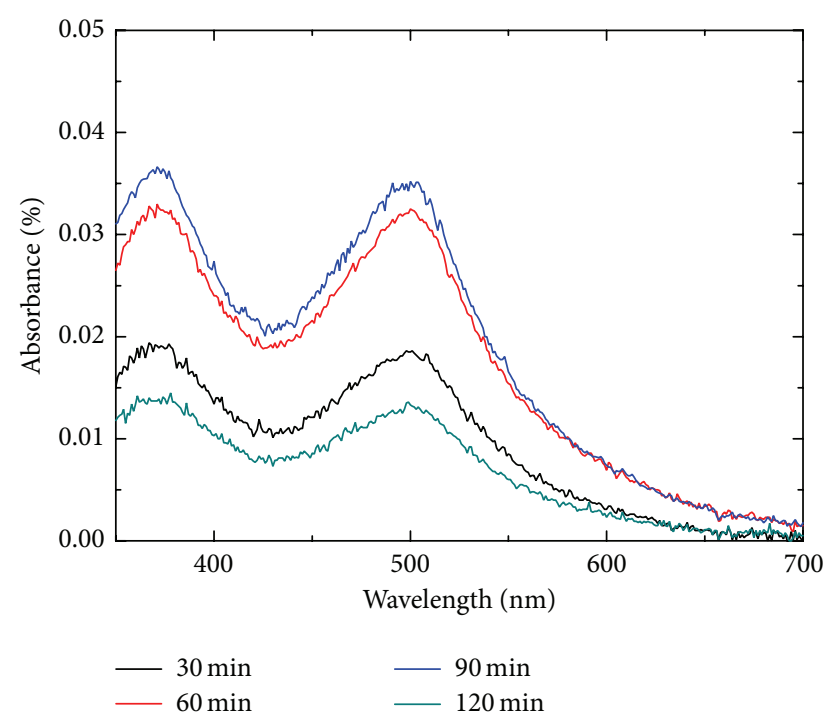

FIGURE 3: UV-visible spectra of DSSCs with the $\mathrm{ZnO}$ nanowires grown for different time.

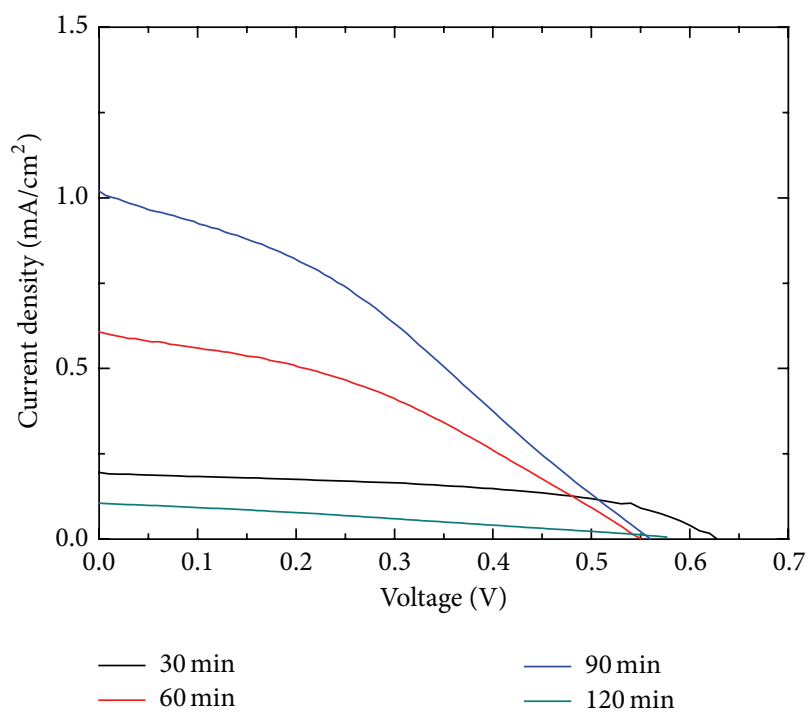

FIgURE 4: $J-V$ characteristic of DSSCs with the $\mathrm{ZnO}$ nanowires grown for different time.

duration was increased to 120 minutes. The $\mathrm{ZnO}$ bottom layer and the length of $\mathrm{ZnO}$ nanowires will become thicker and shorter consequently.

The $J-V$ characteristics for a solar cell with $100 \mathrm{~mW} / \mathrm{cm}^{2}$ broadband illumination from a Xe lamp are shown in Figure 4 . The short-circuit current density (Jsc) of the DSSCs with $\mathrm{ZnO}$ nanowires grown for $30 \mathrm{~min}, 60 \mathrm{~min}, 90 \mathrm{~min}$, and $120 \mathrm{~min}$ is $0.195 \mathrm{~mA} / \mathrm{cm}^{2}, 0.607 \mathrm{~mA} / \mathrm{cm}^{2}, 1.02 \mathrm{~mA} / \mathrm{cm}^{2}$, and $0.105 \mathrm{~mA} / \mathrm{cm}^{2}$, respectively. And the conversion efficiencies are $0.061 \%, 0.092 \%, 0.166 \%$, and $0.018 \%$ for $\mathrm{ZnO}$ nanowires grown for $30 \mathrm{~min}, 60 \mathrm{~min}, 90 \mathrm{~min}$, and $120 \mathrm{~min}$. Jsc can be attributed to the dye loading of $\mathrm{ZnO}$ nanowires, as the photocurrent increased with the dye loading increasing. The

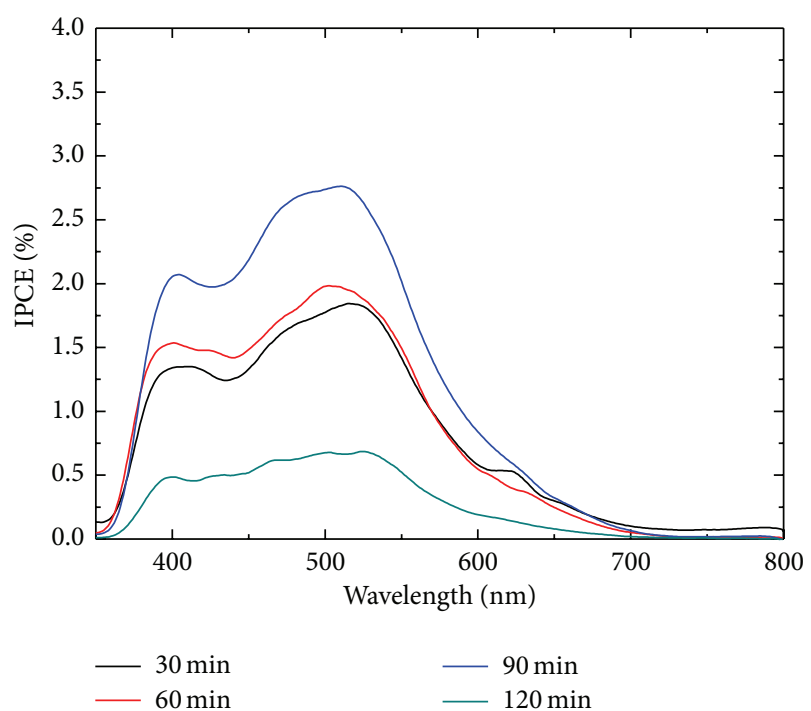

FIGURE 5: IPCE spectra of DSSCs with the $\mathrm{ZnO}$ nanowires with different growth time.

dye loading on the surface of electrode is of much concern for the cell performance. An electrode with larger surface area absorbs more dye molecules. The increased dye loading had played an important role in improving power conversion efficiency. The highest efficiency was observed in DSSC with $\mathrm{ZnO}$ nanowires grown for 90 minutes. The enhancement in Jsc might be originated from the largest equivalent surface area and also the highest dye loading.

Incident photon to current efficiency (IPCE) was determined using a Xe lamp and monochromator for the cells with DSSCs with various nanowire arrays equivalent surface area. Shown in Figure 5 are the IPCE spectra, in which the efficiency at the maximum absorption of the dye (at $525 \mathrm{~nm}$ ) is proportional to the equivalent surface area of $\mathrm{ZnO}$ nanowire arrays. Furthermore, from UV-visible spectroscopy in Figure 3, it is found that the more equivalent surface area of nanowire arrays led more dye loading and enhanced the photo-generated current to increase the light harvesting effects. The highest efficiency was observed in DSSC sample with $\mathrm{ZnO}$ nanowires grown for 90 minutes, which had the largest equivalent surface area and also the highest dye loading. In addition, another photocurrent peak at $380 \mathrm{~nm}$ is clearly observed in Figure 5. The photocurrent peak is attributed to the light harvesting by the $\mathrm{ZnO}$ nanowires.

To further elucidate the role of $\mathrm{ZnO}$ nanowires in the charge transfer properties of DSSCs, we carried out an alternating current (AC) impedance measurement with a Nyquist plot in an EIS system and the results are plotted in Figure 6. The resistance is extracted from the Nyquist plot in Figure 6, and shown in the inset is the equivalent circuit model where $R_{h}$ is the resistance of the TCO substrate, $R_{1}$ is related to charge transport at the Pt counter electrode, $R_{2}$ is related to charge transport at the $\mathrm{ZnO}$ nanowires, $R_{3}$ is the diffusion effects within the electrolyte, and CPE is the constant phase element. From the extracted values, $R_{2}$ have 


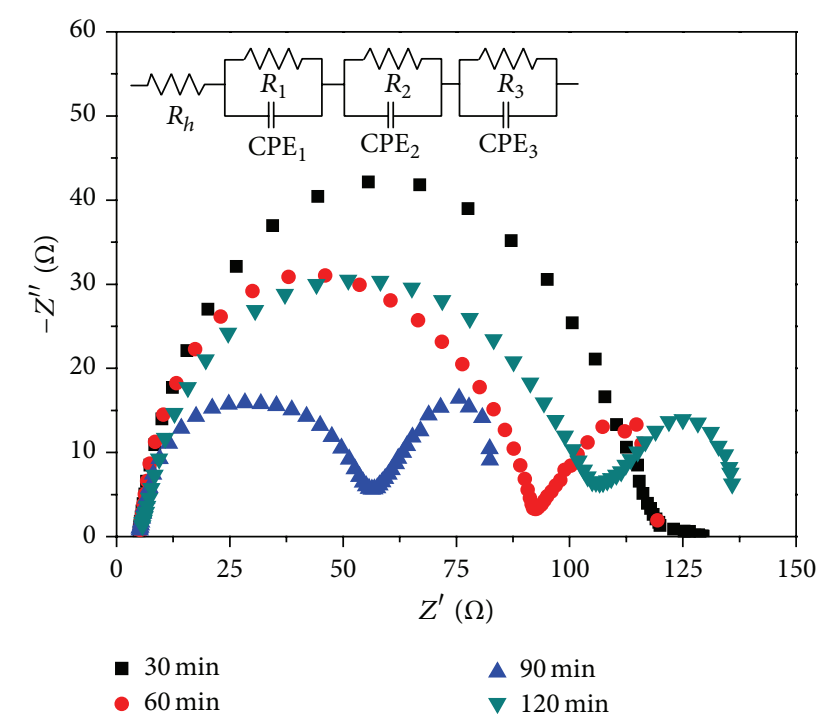

FIGURE 6: EIS spectra of DSSCs with the $\mathrm{ZnO}$ nanowires grown at different time, and shown in the inset is the equivalent circuit model.

saliently changed which is related to the $\mathrm{ZnO}$ nanowire photoanode. As the equivalent surface area of nanowire arrays increased, the resistance of $R_{2}$ had decreased. It is indicated that the resistance $\left(R_{2}\right)$ has direct relation with dye loading. Furthermore, the $R_{2}$ value of DSSC with nanowires grown for 120 min was measured under illumination and is smaller than in dark. So $R_{2}$ can be considered as the impedance between the dye and the $\mathrm{ZnO}$ nanowires photoanode after illumination. From the above impedance analysis, the dye loading has held great importance in the impedance analysis. The more dye loading of the cell had the less resistance and the lower inner resistance of DSSCs, and it effectively reduced the recombination during the electrons transport. From the results, the sample with $\mathrm{ZnO}$ nanowires grown for 90 minutes has the highest photoelectric conversion efficiency and the lowest resistance, and the enhancement is attributed to the contribution of the largest equivalent surface area of $\mathrm{ZnO}$ nanowire arrays.

\section{Conclusion}

In summary, $\mathrm{ZnO}$ nanowires arrays have been grown on FTO substrate via a simple vapor-phase transport process in a horizontal tube furnace. As the $\mathrm{ZnO}$ nanowire arrays applied to the dye-sensitized solar cell, the dye loading is proportional to the total surface area of $\mathrm{ZnO}$ nanowire arrays in the cell and has played an important role in improving power conversion efficiency. The more dye loading of the cell had the less resistance, and the lower inner resistance of DSSCs can effectively reduce the recombination during the electrons transport. From the results, DSSC with $\mathrm{ZnO}$ nanowires grown for 90 minutes has the highest photoelectric conversion efficiency and the lowest resistance which have the largest equivalent surface area of $\mathrm{ZnO}$ nanowire arrays. Though the conversion efficiency $(0.166 \%)$ is lower than the $\mathrm{TiO}_{2}$-based cells, further improvement of $1 \mathrm{D} \mathrm{ZnO}$-based cell is underway for high illumination without filtering the UV from the visible light.

\section{Conflict of Interests}

The authors declare that there is no conflict of interests regarding the publication of this paper.

\section{Acknowledgments}

This work was supported by the Green Technology Research Center of Chang Gung University and the National Science Council (NSC) of Taiwan under Contract no. NSC-101-2112M-182-003-MY3.

\section{References}

[1] B. O'Regan and M. Gratzel, "A low-cost, high-efficiency solar cell based on dye-sensitized colloidal $\mathrm{TiO}_{2}$ films," Nature, vol. 353, pp. 737-740, 1991.

[2] M. K. Nazeeruddin, A. Kay, I. Rodicio et al., "Conversion of light to electricity by cis-X2bis $\left(2,2^{\prime}\right.$-bipyridyl- $4,4^{\prime}$ dicarboxylate)ruthenium(II) charge-transfer sensitizers (X = $\mathrm{Cl}-, \mathrm{Br}-, \mathrm{I}-, \mathrm{CN}-$, and SCN-) on nanocrystalline $\mathrm{TiO}_{2}$ electrodes," Journal of the American Chemical Society, vol. 115, no. 14, pp. 6382-6390, 1993.

[3] A. Hagfeldt and M. Gratzel, "Light-induced redox reactions in nanocrystalline systems," Chemical Reviews, vol. 95, no. 1, pp. 49-68, 1995.

[4] N. Kopidakis, N. R. Neale, K. Zhu, J. van de Lagemaat, and A. J. Frank, "Spatial location of transport-limiting traps in $\mathrm{TiO}_{2}$ nanoparticle films in dye-sensitized solar cells," Applied Physics Letters, vol. 87, no. 20, Article ID 202106, pp. 1-3, 2005.

[5] S. Burnside, S. Winkel, K. Brooks et al., "Deposition and characterization of screen-printed porous multi-layer thick film structures from semiconducting and conducting nanomaterials for use in photovoltaic devices," Journal of Materials Science: Materials in Electronics, vol. 11, no. 4, pp. 355-362, 2000.

[6] J. E. Rowe, M. Cardona, and F. H. Pollak, "Valence band symmetry and deformation potentials of $\mathrm{ZnO}$," Solid State Communications, vol. 6, no. 4, pp. 239-242, 1968.

[7] S. Y. Kuo, W. C. Chen, F. I. Lai et al., "Effects of doping concentration and annealing temperature on properties of highlyoriented Al-doped ZnO films," Journal of Crystal Growth, vol. 287, no. 1, pp. 78-84, 2006.

[8] S. Y. Kuo, F. I. Lai, W. C. Chen, C. P. Cheng, H. C. Kuo, and S. C. Wang, "Ultraviolet lasing of sol-gel-derived zinc oxide polycrystalline films," Japanese Journal of Applied Physics, vol. 45, no. 4, pp. 3662-3665, 2006.

[9] R. Tao, T. Tomita, R. A. Wong, and K. Waki, "Electrochemical and structural analysis of Al-doped $\mathrm{ZnO}$ nanorod arrays in dyesensitized solar cells," Journal of Power Sources, vol. 214, pp. 159165,2012

[10] Y. M. Lee and H. W. Yang, "Optimization of processing parameters on the controlled growth of $\mathrm{ZnO}$ nanorod arrays for the performance improvement of solid-state dye-sensitized solar cells," Journal of Solid State Chemistry, vol. 184, no. 3, pp. 615-623, 2011.

[11] A. Qurashi, M. F. Hossain, M. Faiz, N. Tabet, M. W. Alam, and N. K. Reddy, "Fabrication of well-aligned and dumbbell-shaped 
hexagonal $\mathrm{ZnO}$ nanorod arrays and their dye sensitized solar cell applications," Journal of Alloys and Compounds, vol. 503, no. 2, pp. L40-L43, 2010.

[12] Y. Z. Zheng, X. Tao, L. X. Wang et al., "Novel ZnO-based film with double light-scattering layers as photoelectrodes for enhanced efficiency in dye-sensitized solar cells," Chemistry of Materials, vol. 22, no. 3, pp. 928-934, 2010.

[13] J. B. Chu, S. M. Huang, D. W. Zhang et al., "Nanostructured ZnO thin films by chemical bath deposition in basic aqueous ammonia solutions for photovoltaic applications," Applied Physics A: Materials Science and Processing, vol. 95, no. 3, pp. 849-855, 2009.

[14] H. R. Pant, C. H. Park, B. Pant, L. D. Tijing, H. Y. Kim, and C. S. Kim, "Synthesis, characterization, and photocatalytic properties of $\mathrm{ZnO}$ nano-flower containing $\mathrm{TiO}_{2} \mathrm{NPs}$," Ceramics International, vol. 38, no. 4, pp. 2943-2950, 2012.

[15] Y. Wu. H. Yan, M. Huang, B. Messer, J. Song, and P. Yang, "Inorganic semiconductor nanowires: rational growth, assembly, and novel properties," Chemistry, vol. 8, no. 6, p. 1260, 2002.

[16] J. Zhong, S. Muthukumar, Y. Chen et al., "Ga-doped ZnO singlecrystal nanotips grown on fused silica by metalorganic chemical vapor deposition," Applied Physics Letters, vol. 83, no. 16, pp. 3401-3403, 2003.

[17] R. C. Wang, C. P. Liu, J. L. Huang, and S. J. Chen, Applied Physics Letters, vol. 86, no. 25, Article ID 251104, 2005.

[18] L. Guo, Y. L. Ji, H. Xu, P. Simon, and Z. Wu, "Regularly shaped, single-crystalline $\mathrm{ZnO}$ nanorods with wurtzite structure," Journal of the American Chemical Society, vol.124, no. 50, pp. 1486414865, 2002. 

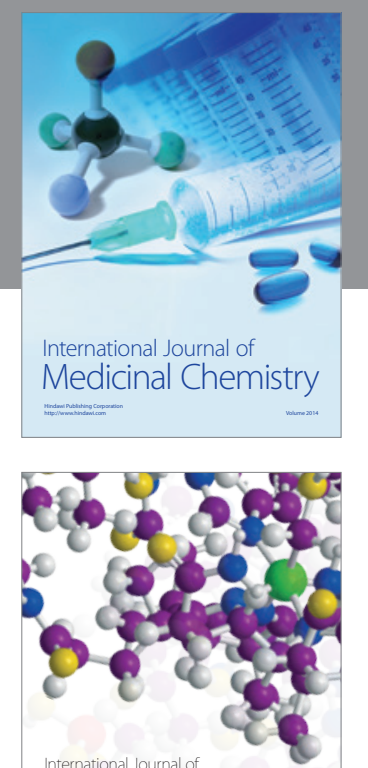

\section{Carbohydrate} Chemistry

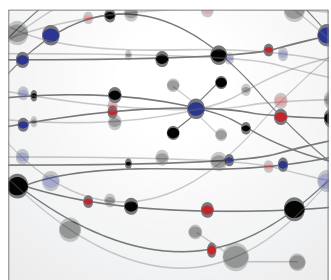

The Scientific World Journal
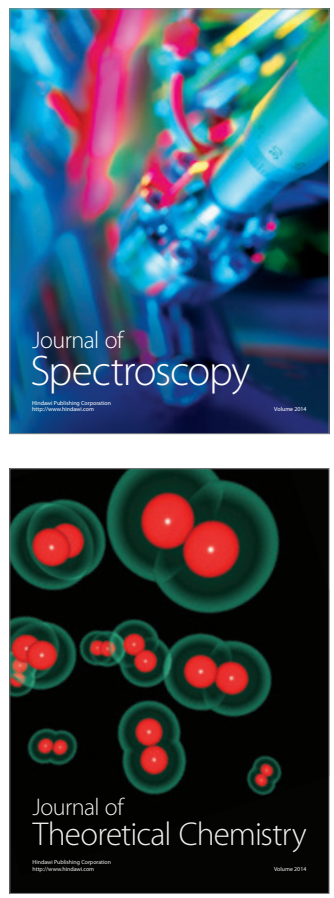
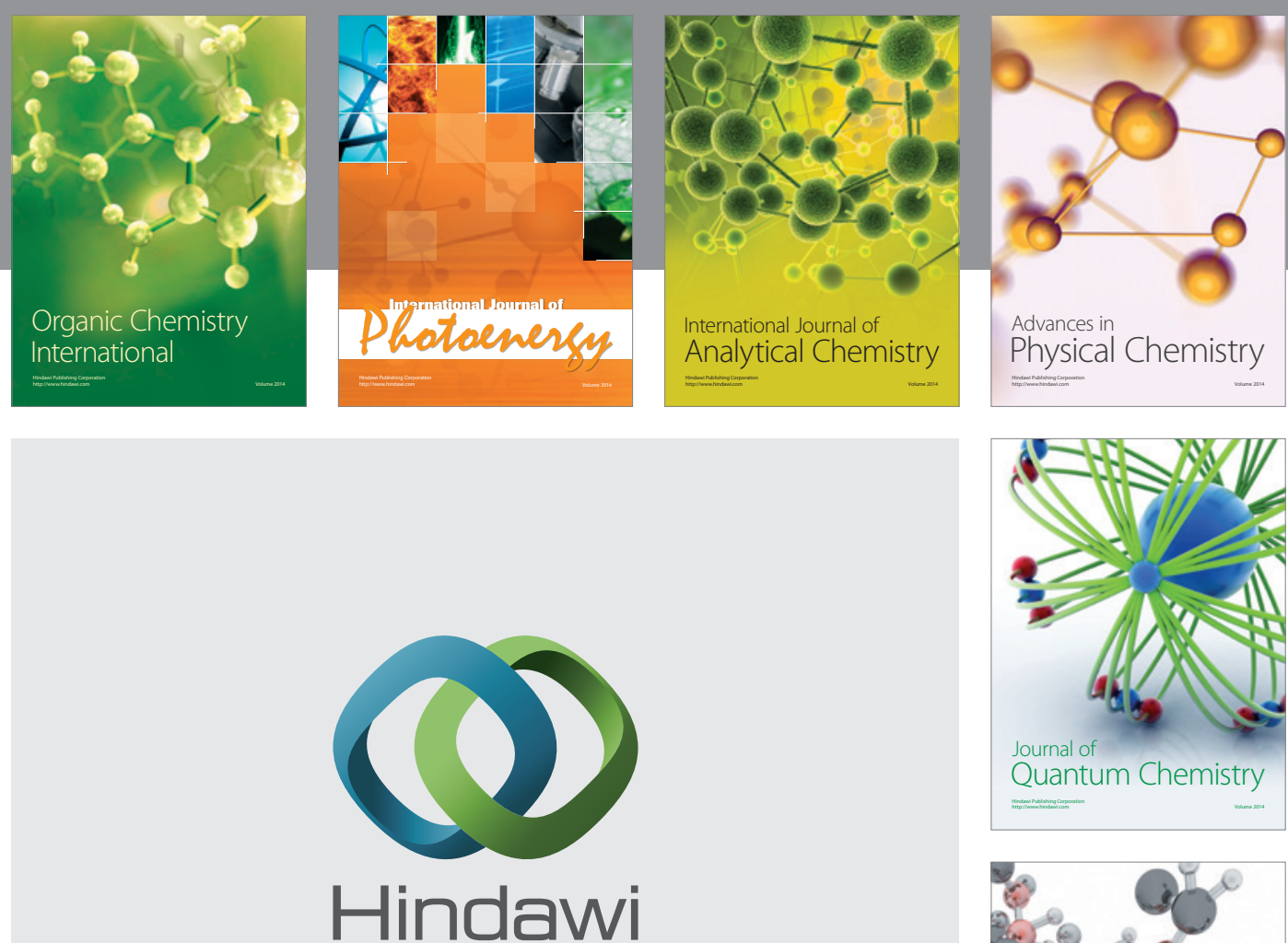

Submit your manuscripts at

http://www.hindawi.com

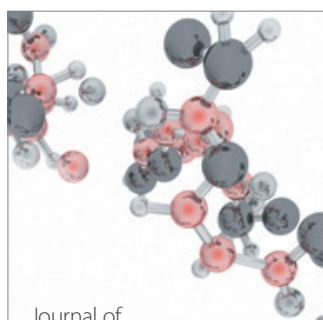

Analytical Methods

in Chemistry

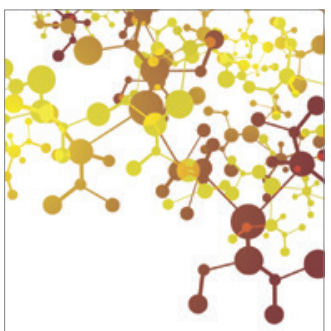

Journal of

Applied Chemistry

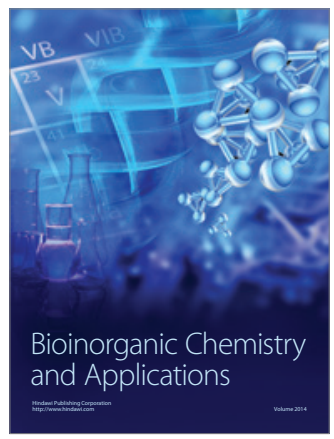

Inorganic Chemistry
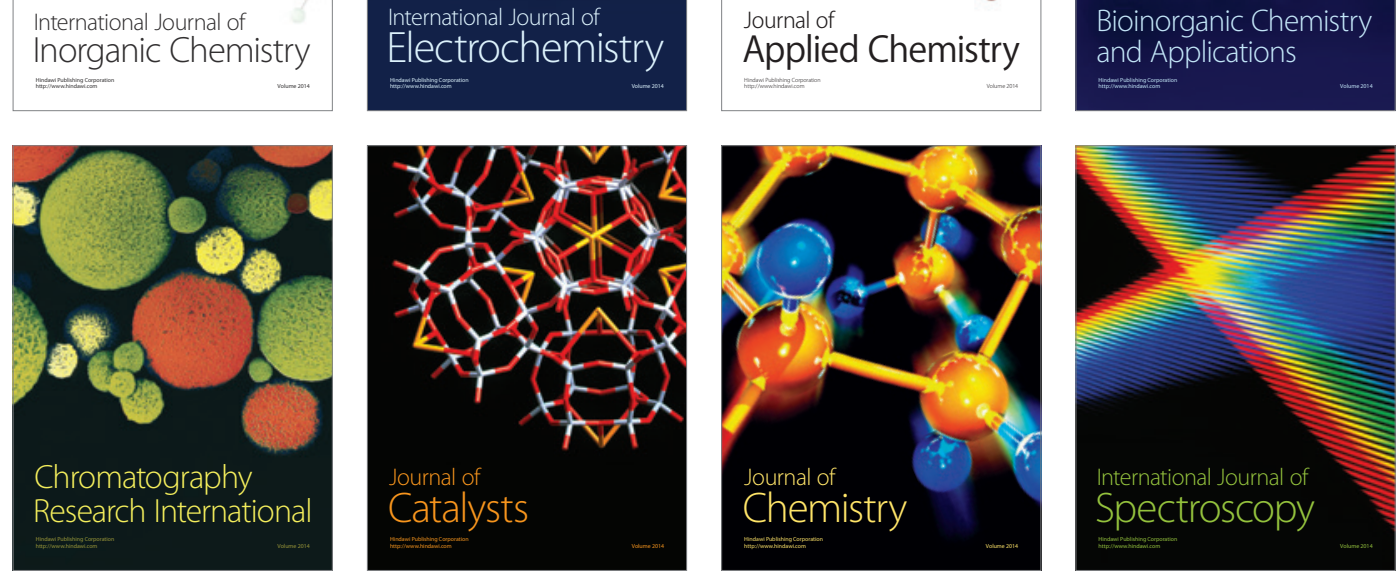